\title{
Mucoepidermoid carcinoma in Warthin tumor of the parotid gland
}

Wojciech Smółka ${ }^{1}$, Jarosław Markowski ${ }^{1}$, Agnieszka Piotrowska-Seweryn ${ }^{1}$, Piotr Paleń ${ }^{2}$, Zuzanna Dobrosz ${ }^{2}$, Włodzimierz Dziubdziela ${ }^{3}$

\author{
${ }^{1}$ Department of Laryngology, School of Medicine in Katowice, Medical University \\ of Silesia, Katowice, Poland \\ ${ }^{2}$ Department of Histopathology, School of Medicine in Katowice, Medical University \\ of Silesia, Katowice, Poland \\ ${ }^{3}$ The Chronic Pain Clinic, Sosnowiec, Poland
}

Submitted: 8 July 2013

Accepted: 3 September 2013

Arch Med Sci 2015; 11, 3: 691-695

DOI: 10.5114/aoms.2015.52379

Copyright $\odot 2015$ Termedia \& Banach

Neoplasms of salivary glands are responsible for ca. $3-5 \%$ of head and neck tumors, and they usually occur in the parotid gland (80\%) as benign tumors (80\%). Localization in submandibular salivary glands is reported in $10-20 \%$ of cases, and tumors sited in sublingual and minor salivary glands are very rare (several percent) [1]. Among benign neoplasms the following types have been identified: pleomorphic adenoma (80\%), adenolymphoma (12\%) and others (2\%) [2].

Warthin tumor (WT), known as adenolymphoma, papillary cystadenoma, cystadenolymphoma and epitheliolymphoid cyst, is the second most common benign tumor of the parotid gland [3-5], after pleomorphic adenoma, and it represents $5-11 \%$ of primary tumors in salivary glands $[3,6]$. It occurs mainly in the parotid gland synchronously or metachronously in the same or contralateral gland [1,3]. Multifocal localization is reported in ca. $5 \%$ of cases [1]. Warthin tumor affects mainly males in the $6^{\text {th }}$ and $7^{\text {th }}$ decade $[1,3,7,8]$. Recently, an increasing incidence for females has been reported [9]. The etiology of WT remains unknown, but studies on its connection with progesterone receptors [10] and smoking [9] are reported.

Warthin tumor manifests as a slowly growing, freely moveable, painless soft tissue mass located in the superficial lobe of the parotid gland $[1,9]$. Ultrasound examination reveals the presence of a well-defined hypoechoic mass [1, 3]. A fine-needle aspiration biopsy (FNAB) is essential in order to complete diagnosis. Histologically, WT consists of two tissues, lymphoid stroma and glandular epithelium with characteristic eosinophilic cytoplasm, and the latter is often papillary $[3,5,11]$.

Treatment of WT usually includes surgical management, but there is a lot of controversy concerning the appropriate extent surgery [1,9]. It is claimed that limited excisions, such as enucleation or removal of the inferior half of the superficial lobe, are sufficient [12-15]. The standard treatment in our department includes classic superficial parotidectomy. Manifestation of a tumor in the inner lobe requires total parotidectomy.

Malignant transformation of WT is quite common in the case of the lymphoid component, while malignant carcinoma is a rare entity $(0.3 \%$ cases) $[7,16]$ and was first reported by Ruebner and Bramhall in 1960 [17]. Carcinomatous components can be represented by squamous cell carcinoma (the most common) [18-20], oncocytic carcinoma, adenocar-

\author{
Corresponding author: \\ Agnieszka Piotrowska- \\ Seweryn MD \\ Department of Laryngology \\ Medical University of Silesia \\ 20-24 Francuska St \\ 40-027 Katowice, Poland \\ Phone: +48 696729897 \\ E-mail: agapio.fm@interia.pl
}


cinoma, undifferentiated carcinoma and mucoepidermoid carcinoma (MEC) [21-25].

We report a case of MEC arising in WT of the parotid gland, describing clinical and pathological aspects.

A case of a 61-year-old male patient treated in our department due to a tumor in the region of the mandibular angle on the left side, gradually enlarging in a 6-month period, was analyzed. Additional diseases included hypertension. The patient had undergone superficial parotidectomy of the right parotid gland due to WT 1 year before admission. Family medical history was insignificant. Neither alcohol consumption nor allergies were reported. The patient was a long-term smoker (20 cigarettes per day).

On admission to hospital an asymptomatic, partly moveable soft tumor of $2 \mathrm{~cm}$ in diameter was palpable in the region of the left parotid gland. No enlarged cervical lymph nodes were found in physical examination. The FNAB of the tumor revealed the presence of neoplastic cells, probably carcinomatous. Left total parotidectomy

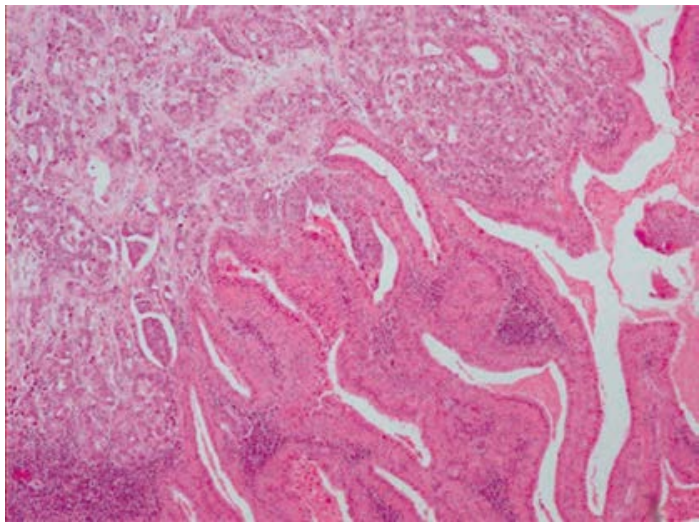

Figure 1. High-grade mucoepidermoid carcinoma (upper left) derived from WT (lower right). Magnification $4 \times$

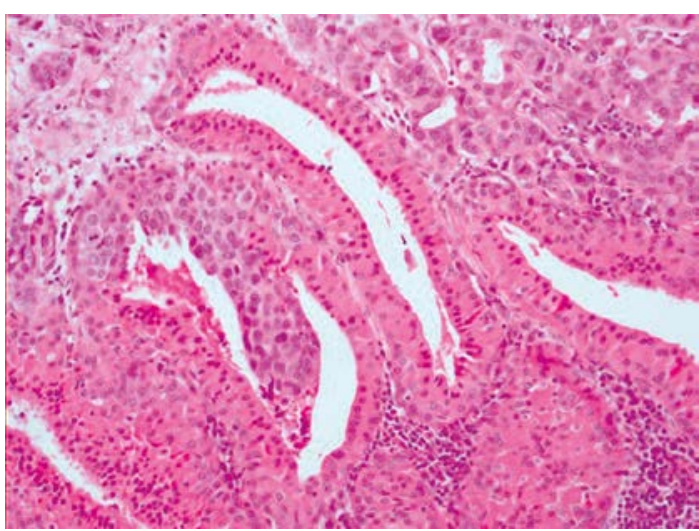

Figure 2. High-grade mucoepidermoid carcinoma derived from WT. Residual non-invasive tumor component formed of double-layered oxyphilic tubules in close association with high-grade invasive carcinoma with partial solid partial tubular appearance. Magnification 10× with facial nerve preservation as well as excision of cervical lymph nodes on the left side was performed. The parotid gland had the dimensions $6 \times 4 \times 4.5 \mathrm{~cm}$ and it contained a tumor of $1.8 \mathrm{~cm}$ in diameter, which infiltrated the sternocleidomastoid muscle. No postoperative complications were observed.

Morphological examination of the material showed carcinomatous infiltration in the adjacent lipomatous tissue and a WT with a malignant transformation into MEC (Figure 1). The epithelial component formed of double-layered oxyphilic tubules in close association with high-grade invasive carcinoma with partially solid, partially tubular appearance was observed (Figure 2). Immunohistochemical profile of the WT and MEC arising within it was revealed thanks to 26 immunohistochemical examinations (Table I). A great similarity among cytokeratin antibodies, especially CK7 and CK19, was found (Figure 3). p63 nuclear staining acted as a differentiating examination between

Table I. Immunohistochemical results of Warthin tumor and MEC in WT

\begin{tabular}{|c|c|c|}
\hline Antibody & Warthin tumor & $\begin{array}{c}\text { MEC in Warthin } \\
\text { tumor }\end{array}$ \\
\hline CK (AE1/AE3) & + & + \\
\hline CK 5/6 & + & + \\
\hline CK 7 & ++ & +++ \\
\hline CK 19 & +++ & +++ \\
\hline CK 20 & - & - \\
\hline CK $34 \beta E 12$ & + & Focal + \\
\hline CEA & - & - \\
\hline E-cadherin & +++ & +++ \\
\hline B-catenin & $-1+$ & $-1+$ \\
\hline p16 & - & - \\
\hline p53 & - & Focal + \\
\hline p63 & ++ & - \\
\hline EMA & + & ++ \\
\hline MUC 1 & ++ & +++ \\
\hline MUC 2 & - & - \\
\hline Calponin & + & ++ \\
\hline bcl-2 & $-1+$ & $-1+$ \\
\hline HER-2 & - & - \\
\hline Ki-67 & $1 \%$ & $12 \%$ \\
\hline Lysozyme & - & - \\
\hline Nestin & $-1+$ & $-1+$ \\
\hline WT-1 & $-1+$ & $-1+$ \\
\hline Racemase & - & - \\
\hline S-100 & - & - \\
\hline SMA & - & - \\
\hline Actin & - & - \\
\hline
\end{tabular}




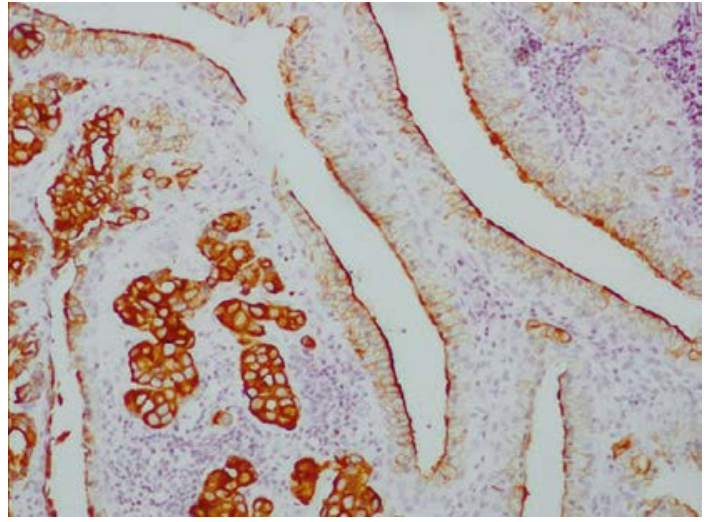

Figure 3. Luminal component of WT and mucoepidermoid carcinoma labeled with cytokeratin-7 antibody. Magnification 10x

carcinoma cells and WT cells (Figure 4). Positive reactions in both tissues were found when analyzing E-cadherin, MUC-1 and calponin. A lot of similarities in negative immunohistochemical findings, mainly concerning CK20, p16, MUC-2, HER-2, lysozyme, racemase, S-100, SMA and actin, were reported.

No metastases in the lymph nodes were found.

The surgical management was followed by adjunctive 6-week radiotherapy with a total dose of 65 Gy. To date he remains under continuous observation in the outpatient department with no local recurrence.

Mucoepidermoid carcinoma in WT of the parotid gland seems to be a rare entity, and it is mentioned by several authors. So far, 19 cases of WT co-existing with MEC have been reported (Table II).

The etiology of WT lesions remains unclear, but two hypotheses have been suggested: non-neoplastic proliferation manifested as oncocytic cellular hyperplasia, and the other based on a clonal derivation resulting in oncocytic neoplastic growth [26]. Warthin tumor often appears synchronously or metachronously in the same or contralateral gland $[1,3]$. In our study Warthin tumor with MEC of the left parotid gland was diagnosed 1 year after the patient underwent superficial parotidectomy due to WT of the contralateral parotid gland. As the above situation is commonly observed, this aspect does not need any further explanation.

Mucoepidermoid cancer usually occurs in major or minor salivary glands as well as trachea and bronchi. According to Barnes et al., the ratio for major and minor salivary glands is $50: 50$ [27]. The MEC is responsible for $5 \%$ of all salivary gland tumors and $20 \%$ of the malignancies [28].

The histopathologic findings positively correspond with the research of other authors, although selection of cases with 'pure' MEC in WT still remains extremely difficult.

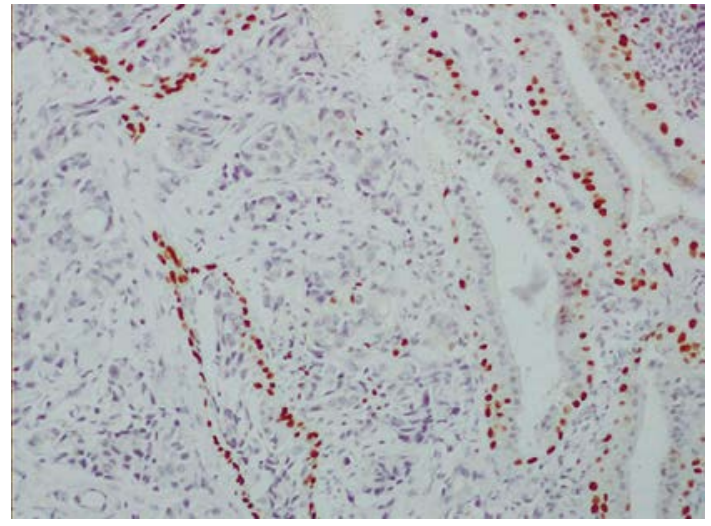

Figure 4. p63 nuclear staining in abluminal cells of WT. No staining in carcinoma cells

Table II. List of publications in which the authors mention the cases of mucoepidermoid carcinoma in Warthin tumor

\begin{tabular}{|lcc|}
\hline $\begin{array}{l}\text { Author } \\
\text { [reference no.] }\end{array}$ & $\begin{array}{c}\text { Year } \\
\text { of publication }\end{array}$ & $\begin{array}{c}\text { Number } \\
\text { of cases reported }\end{array}$ \\
\hline Gadient [34] & 1975 & 1 \\
\hline Gnepp [35] & 1989 & 1 \\
\hline Saku [37] & 1997 & 1 \\
\hline Seifert [38] & 1997 & 1 (bilaterally) \\
\hline Nagao [5] & 1998 & 5 \\
\hline Williamson [11] & 2000 & 1 \\
\hline Curry [36] & 2002 & 1 \\
\hline Yamada [4] & 2002 & 1 \\
\hline Martins [32] & 2004 & 1 \\
\hline Mardi [39] & 2007 & 3 \\
\hline Bell [26] & 2008 & 1 \\
\hline Mohapatra [7] & 2012 & 2 \\
\hline
\end{tabular}

When reporting microscopic findings in Warthin tumor, Srivastava et al. described cystic spaces lined by a double layer of cuboidal to tall columnar, eosinophilic, oncocytic epithelial cells next to stroma composed of abundant lymphoid tissue and another neoplasm with highly atypical, large epidermoid cells acting as MEC [29]. In our study we report the presence of an epithelial component formed of double-layered oxyphilic tubules in close association with high-grade invasive carcinoma with partially solid, partially tubular appearance.

According to Mohapatra et al., epithelial neoplastic tissue can appear in WT under the following types: 1) co-existing separate neoplasm, e.g. pleomorphic adenoma - the most common type; 2) metastatic tissue of another head and neck carcinoma; 3) primary carcinoma arising in the epithelial component [30]. 
In order to diagnose the latter, it is essential to find the bulk of the carcinoma inside the WT, and the oncocytic epithelium should contain transitional zones from a hyperplastic/dysplastic state to malignancy. The metaplasia alteration can be the result of inflammation or infarction [30]. Similar findings were presented by Yamada et al. [4]. The characteristics mentioned above could also be observed in our study.

Furthermore, Yamada et al., Williamson et al. and Manisha et al. maintain that exclusion of metastases to the stromal component of the tumor is one of the criteria of diagnosing malignant transformation of WT. The most common metastases to the parotid gland originate from head and neck squamous cell carcinomas, lung, breast and colon cancer. Due to the fact that metastases mimic squamous or adenoid carcinoma in histopathological examination, the diagnosis should be based on clinical findings. Therefore, in our study metastases were excluded by the clinical history and physical examination.

However, the recent studies focus on immunohistochemical examinations [31]. The immunohistochemical profile of the WT and MEC arising within WT was also determined in our study. The findings prove the presence of MEC in Warthin tumor and exclude the existence of metastases. Such evidence is crucial in cases when revealing the continuous tissue transformation after performing basic histopathological examination remains uncertain. In our study the presence of malignant transformation of WT is undoubted (Figure 1). The only differences were observed when analyzing p63 and Ki-67. However, these antibodies are often used to differentiate between benign and malignant tissues, as can be found in our results (Figure 4).

Finally, molecular analysis of MEC, especially those with synchronous Warthin tumor, is a matter of many recent studies. Namely, it has been found that MEC can be associated with recurring chromosomal translocation $\mathrm{t}(11 ; 19)$ (q21;p13), which results in the fusion transcript MECT1-MAML2. According to Martins et al., this translocation might be pathognomonic for MEC, mainly if it occurs as the sole cytogenetic abnormality [32], and it is rarely observed in WT. Also, Okabe et al. presented a study of 71 patients with mucoepidermoid tumor, among whom MECT1-MAML2 fusion, which corresponded with a less advanced clinical stage and lower histologic grade, was observed in 27 cases. Moreover, longer disease-free and overall survival was observed in the fusion positive cases [28].

Other authors, such as Tirado et al., performed molecular analyses of CRTC1/MAML2 fusion in both fresh and paraffin tissue samples. They proved that negative tumors correspond with distant metastases and that the presence of the $t(11 ; 19)$ translocation increases the risk of phenotypic and biological lesions, such as WT. The researchers presented the occurrence of the fusion in WT, in contrast to the studies of Okabe and Martins, as the effect of the modified method applied (fresh specimens) [33]. Similar results were obtained in 2008 by Bell et al., who stated that there is a histogenetic link between WT and MEC [26]. Moreover, they tried to explain the possible evolution of WT and related carcinomas based on the molecular findings of $t(11 ; 19)$ translocation. According to the observations, mitochondrial alteration of salivary duct cells leads to oncocytic ductal features. Afterwards, nonclonal oncocytic cellular proliferation resulting in nodular hyperplasia (WT) is observed or clonal oncocytic growth induced by CTRCT1/MAML2 gives rise to WT prone to malignancy. The last step leads to transformation either into malignant WT or MEC (on the basis of metaplasia) [26].

The lack of molecular analysis in our study is one of the main limitations, which prevents further discussion and any comparison. Nevertheless, the authors hope to present a complementary explanation soon.

In conclusion, mucoepidermoid carcinoma in WT is a rare entity. However, thanks to rapidly developing molecular studies, there is a hope for establishment of a definite explanation of its origin, which might result in easy diagnosis of similar cases in the future.

\section{Conflict of interest}

The authors declare no conflict of interest.

References

1. Szyfter W. Nowotowory w otorynolaryngologii. Termedia, Poznan 2012; 149-76.

2. Behrbohm H, Kaschke O, Nawka T, Swift A. Ear, nose, and throat diseases with head and neck surgery. 3rd edn. Elsevier Urban \& Partner, Wrocław 2011; 434-44.

3. Gorai S, Numata T, Kawada S, Nakano M, Tamaru J, Kobayashi T. Malignant lymphoma arising from heterotopic Warthin's tumor in the neck: case report and review of the literature. Tohoku J Exp Med 2007; 212: 199-205.

4. Yamada S, Matsuo T, Fujita S, Suyama K, Yamaguchi A, Mizuno A. Mucoepidermoid carcinoma arising in Warthin's tumor of the parotid gland. Pathol Int 2002; 52: 653-6.

5. Nagao T, Sugano I, Ishida Y, et al. Mucoepidermoid carcinoma arising in Warthin's tumour of the parotid gland: report of two cases with histopathological, ultrastructural and immunohistochemical studies. Histopathology 1998; 33: 379-86.

6. Ellis GL, Auclair PL. Tumors of the salivary glands. Armed Forces Institute of Pathology, Washington DC 1996.

7. Mohapatra M, Satyanarayana S. Low grade mucoepidermoid carcinoma in a setting of Warthin's tumor. Indian J Pathol Microbiol 2012; 55: 392-4. 
8. Cheuk W, Chan JKC. Salivary gland tumors. In: Diagnostic histopathology of tumors. Fletcher CDM (ed.). 2nd edn. Churchill Livingstone, Edinburgh 2002; 231-66.

9. Klussmann J, Wittekindt C, Florian Preuss S, Al Attab A, Schroeder U, Guntinas-Lichius O. High risk for bilateral Warthin tumor in heavy smokers: review of 185 cases. Acta Otolaryngol 2006; 126: 1213-7.

10. Teymoortash A, Werner JA. Tissue that has lost its track: Warthin's tumour. Virchows Arch 2005; 446: 585-8.

11. Williamson JD, Simmons BH, el-Naggar A, Medeiros LJ. Mucoepidermoid carcinoma involving Warthin tumor. A report of five cases and review of the literature. Am J Clin Pathol 2000; 114: 564-70.

12. Iwai H, Yamashita T. Local excision procedure for Warthin's tumor of the parotid gland. Otolaryngol Head Neck Surg 2005; 132: 577-80.

13. McGurk M, Thomas BL, Renehan AG. Extracapsular dissection for clinically benign parotid lumps: reduced morbidity without oncological compromise. $\mathrm{Br} J$ Cancer 2003; 89: 1610-3.

14. Rea JL. Partial parotidectomies: morbidity and benign tumor recurrence rates in a series of 94 cases. Laryngoscope 2000; 110: 924-7.

15. Yu GY, Ma DQ, Liu XB, Zhang MY, Zhang Q. Local excision of the parotid gland in the treatment of Warthin's tumour. Br J Oral Maxillofac Surg 1998; 36: 186-9.

16. Bolat F, Kayaselcuk F, Erkan AN, Cagici CA, Bal N, Tuncer I. Epidermoid carcinoma arising in Warthin's tumor. Pathol Oncol Res 2004; 10: 240-2.

17. Ruebner B, Bramhall JL. Malignant papillary cystadenoma lymphomatosum. Arch Pathol 1960; 69: 110-7.

18. Baker M, Yuzon D, Baker BH. Squamous cell carcinoma arising in benign adenolymphoma (Warthin's tumor) of the parotid gland. J Surg Oncol 1980; 15: 7-10.

19. McClatchey KD, Appelblatt NH, Langin JL. Carcinoma in papillary cystadenoma lymphomatosum (Warthin's tumor). Laryngoscope 1982; 92: 98-9.

20. Damjanov I, Sneff EM, Delerme AN. Squamous cell arcinoma arising in Warthin's tumor of the parotid gland: a light, electron microscopic, and immunohistochemical study. Oral Surg Oral Med Oral Pathol 1983; 55: 286-90.

21. De la Pava S, Knutson GH, Mukhtar F, Pickren JW. Squamous cell carcinoma arising in Warthin's tumor of the parotid gland. Cancer 1965; 18: 790-4.

22. Assor D. Bilateral carcinoma of parotid, one cancer arising in a Warthin's tumor. Am J Clin Pathol 1974; 61: 270-4.

23. Kessler E, Koznizky IL, Schindel J. Malignant Warthin's tumor. Oral Surg Oral Med Oral Pathol 1977; 43: 111-5.

24. Baker M, Yuzon D, Baker BH. Squamous cell carcinoma arising in benign adenolymphoma (Warthin's tumor) of the parotid gland. J Surg Oncol 1980; 15: 7-10.

25. Moosavi H, Ryan C, Schwartz S, Donnelly JA. Malignant adenolymphoma. Hum Pathol 1980; 11: 80-3.

26. Bell D, Luna MA, Weber RS, Kaye FJ, El-Naggar AK. CRTC1/MAML2 fusion transcript in Warthin's tumor and mucoepidermoid carcinoma: evidence for a common genetic association. Genes Chromosomes Cancer 2008; 47: 309-14.

27. Barnes L, Eveson J, Reichart P, Sidransky D (eds). Pathology and genetics of tumours of the head and neck. WHO classification of tumours. IARC Press, Lyon 2005.

28. Okabe M, Miyabe S, Nagatsuka H, et al. MECT1-MAML2 fusion transcript defines a favorable subset of mucoepidermoid carcinoma. Clin Cancer Res 2006; 12: 3902-7.

29. Srivastava S, Nadelman C. Synchronous ipsilateral Warthin tumor encased by a separate mucoepidermoid car- cinoma of the parotid gland: a case report and review of the literature. Diagn Cytopathol 2010; 38: 533-7.

30. Mohapatra M, Satyanarayana S. Low grade mucoepidermoid carcinoma in a setting of Warthin's tumor. Indian J Pathol Microbiol 2012; 55: 392-4.

31. Bell D, Luna MA. Warthin adenocarcinoma: analysis of 2 cases of a distinct salivary neoplasm. Ann Diagn Pathol 2009; 13: 201-7.

32. Martins C, Cavaco B, Tonon G, Kaye FJ, Soares J, Fonseca I. A study of MECT1-MAML2 in mucoepidermoid carcinoma and Warthin's tumor of salivary glands. J Mol Diagn 2004; 6: 205-10.

33. Tirado Y, Williams MD, Hanna EY, Kaye FJ, Batsakis JG, El-Naggar AK. CRTC1/MAML2 fusion transcript in high grade mucoepidermoid carcinomas of salivary and thyroid glands and Warthin's tumors: implications for histogenesis and biologic behavior. Genes Chromosomes Cancer 2007; 46: 708-15.

34. Gadient SE, Kalfayan B. Mucoepidermoid carcinoma arising within a Warthin's tumor. Oral Surg Oral Med Oral Pathol 1975; 40: 391-8.

35. Gnepp DR, Schroeder W, Heffner D. Synchronous tumors arising in a single major salivary gland. Cancer 1989; 63: 1219-24.

36. Curry JL, Petruzzelli GJ, McClatchey KD, Lingen MW. Synchronous benign and malignant salivary gland tumors in ipsilateral glands: a report of two cases and a review of literature. Head Neck 2002; 24: 301-6.

37. Saku T, Hayashi Y, Takahara O, et al. Salivary gland tumors among atomic bomb survivors, 1950-87. Cancer 1997; 79: 1465-75.

38. Seifert G. Bilateral mucoepidermoid carcinomas arising in bilateral pre-existing Warthin's tumours of the parotid gland. Oral Oncol 1997; 33: 284-7.

39. Mardi K, Sharma J. Mucoepidermoid carcinoma arising in Warthin's tumor: a case report. Indian J Pathol Microbiol 2007; 50: 331-3. 